Eur. J. Pers. 21: 45-62 (2007)

Published online 21 June 2006 in Wiley InterScience (www.interscience.wiley.com). DOI: 10.1002/per.596

\title{
Big Five Personality Development in Adolescence and Adulthood
}

\author{
SUSAN J. T. BRANJE ${ }^{1 *}$, CORNELIS F. M. VAN LIESHOUT ${ }^{2}$ \\ and JAN R. M. GERRIS ${ }^{2}$ \\ ${ }^{1}$ Utrecht University, The Netherlands \\ ${ }^{2}$ Radboud University, The Netherlands
}

\begin{abstract}
The present article examines Big Five personality development across adolescence and middle adulthood. Two adolescents and their fathers and mothers from 285 Dutch families rated their own and their family members' personality. Using accelerated longitudinal growth curve analyses, mean level change in Big Five factors was estimated. For boys, Extraversion and Openness decreased and for girls, Extraversion, Agreeableness, Conscientiousness, and Openness increased. Whereas mothers' Emotional Stability and Conscientiousness increased, fathers' Extraversion, Agreeableness, and Emotional Stability decreased. Differences in self-and other-reported personality change were found, as well as interindividual differences in personality change. Results confirm that personality change is possible across the life course but these changes are not similar for all individuals and depend on the type of observer. Copyright (C) 2006 John Wiley \& Sons, Ltd.
\end{abstract}

Key words: Big Five; development; adulthood; adolescence

\section{INTRODUCTION}

Personality characteristics are regarded as biologically based endogenous dispositions that will show continuity over time. It was long thought that personality was set in childhood and adolescence, and was fully developed by the age of 30 (e.g. McCrae \& Costa, 1994). More recent studies suggest, however, that mean-level developmental change of personality traits in midlife and old age is still possible. The present article focuses on mean-level developmental change of personality traits across adolescence and middle adulthood.

From a life-span developmental perspective, mean-level personality changes can be normative and life-course related (Baltes, 1987). These changes may be due to intrinsic

*Correspondence to: Susan J. T. Branje, Research Centre Adolescent Development, Utrecht University, Postbox 80140, 3508TC Utrecht, The Netherlands. E-mail: s.j.t.branje@fss.uu.nl

Contract/grant sponsors: Radboud University; Utrecht University. 
development (McCrae et al., 2000), meaning that as individuals grow older, they become better adapted through social experience. For example, individuals become less impulsive, more norm-adherent, and more skilled in social interaction. Personality development can also be due to role changes across the life course that are in part historically and culturally determined, such as work, marriage and parenthood (Srivastava, John, Gosling, \& Potter, 2003; Van Lieshout, 2000). For example, entering the world of work nowadays may require individuals to behave more conscientious at a later age than in previous decades, whereas the later onset of parenthood may require more Agreeableness at a later age than before. Not everybody needs to show the same developmental pattern over time, however (Baltes). In other words, there might be interindividual differences in the timing and rate of intraindividual personality change.

We will examine development of the Big Five personality factors Extraversion, Agreeableness, Conscientiousness, Emotional Stability and Openness to Experience (Goldberg, 1990). The Big Five have been found in numerous studies using different methods, instruments, samples, languages and cultures (e.g. Goldberg; John, 1990; McCrae \& Costa, 1997, 1999). They are not incompatible with other models of personality (Van Lieshout, 2000) and can be reliably assessed in adolescence (Asendorpf \& Van Aken, 2003; Costa \& McCrae, 1994; De Fruyt, Mervielde, Hoekstra, \& Rolland, 2000).

The idea of normative development towards greater adaptation suggests that with age individuals become more agreeable, conscientious, emotionally stable and open, and somewhat less extraverted. Generally, cross-sectional studies revealed that adolescents are higher in Extraversion and Emotional Stability and lower in Agreeableness and Conscientiousness than adults (Costa \& McCrae, 1994; McCrae et al., 2000). Between the age of 12 and 18, cross-sectional studies revealed that mean levels of Emotional Stability decrease for girls only (McCrae et al., 2002). Mean levels of Extraversion, Agreeableness, and Conscientiousness do not change (McCrae et al., 2002), although Agreeableness and Conscientiousness have also been found to decrease (Allik, Laidra, Realo, \& Pullmann, 2004). Openness was found to increase both cross-sectionally and longitudinally (Allik et al., 2004; McCrae et al., 2002). The consistently found increase in Openness may indicate that adolescents are increasingly appreciating intellectual and creative expressions, or may be related to identity development and exploration of different roles and possibilities.

Based on analyses controlling for effects of period, practice, cohort and sample, Costa and McCrae (1988) concluded that there is no consistent evidence for maturational effects in personality during adulthood. More recent studies show that mean personality change during adulthood is possible. Longitudinal findings showed that the increase in Openness and decrease in Emotional Stability continue for a while during young adulthood (Robins, Fraley, Roberts, \& Trzesniewski, 2001; Vaidya, Gray, Haig, \& Watson, 2002). Cross-sectional studies revealed that later on, Openness tends to decline moderately until the age of 30 years and slower thereafter, whereas Emotional Stability tends to increase (Costa, Herbst, McCrae, \& Siegler, 2000; McCrae et al., 1999, 2000; Srivastava et al., 2003). Whereas Agreeableness and Conscientiousness increase, Extraversion decreases from the age of 18 to older age (Robins et al., 2001; Vaidya et al., 2002). Extraversion and Conscientiousness change strongly from age 18 to 30 years and more slowly thereafter (Costa \& McCrae, 1994, 1997; McCrae et al., 1999; Srivastava et al., 2003; Vaidya et al., 2002). The strongest increase for Agreeableness is reported either from age 18 to 30 (Costa \& McCrae, 1994, 1997; Vaidya et al., 2002), or from age 30 to 40 (Srivastava et al., 2003). 
Gender-specific findings have also been reported. During midlife, both males and females were found to longitudinally decrease in Extraversion and increase in Emotional Stability, but only males decreased in Conscientiousness and Openness and only females increased in Agreeableness (Costa et al., 2000). A cross-sectional study based on a large internet sample reported sharp increases for Emotional Stability only among adult women, resulting in smaller gender differences in Emotional Stability with age (Srivastava et al., 2003). For Extraversion, the results showed slight age-related decreases for women and slight increases for men. The only study using growth curve analyses to examine change in Big Five factors among males from age 43 to 91 revealed stability in Extraversion and a curvelinear pattern for Emotional Stability with decrease followed by increase (Mroczek \& Spiro, 2003).

The results of these studies show that personality change in adulthood occurs, although findings are inconsistent, perhaps because a number of these studies used cross-sectional or relatively short-term longitudinal data. Cross-sectional studies provide evidence for change ingroup data only and do not offer conclusive evidence for within-person changes. Longitudinal studies enable conclusions about changes within individuals, but are usually limited in the developmental time-span they cover and in the number of times personality is assessed. A recent meta-analysis of longitudinal studies on personality change (Roberts, Walton, \& Viechtbauer, 2006a) indicated that changes in most personality factors are not constrained to the adolescent or young adulthood period, although most development occurs in young adulthood (20 to 40 years). Results showed that people become more extraverted, conscientious, and emotionally stable with age. On Openness, people show curvilinear patterns of change with increase in adolescence and decrease in old age. Agreeableness increased only in old age.

Longitudinal studies on personality development using advanced methods like growth curve modelling or hierarchical linear modelling are sparse and usually focused on other personality measures (e.g. Jones, Livson, \& Peskin, 2003; Jones \& Meredith, 1996). To our knowledge, growth curve modelling has been used to examine mean changes in the Big Five factors Extraversion and Emotional Stability for males only (Mroczek \& Spiro, 2003), and has not been used to examine changes in these factors for females or changes in Agreeableness, Conscientiousness and Openness. Using accelerated growth curve modelling, we will examine personality development in adolescence from 11 to 17 years of age, and in middle adulthood from approximately 35 to 50 years of age. In a previous study we used latent growth modelling to examine personality changes over a 2-year period in parents and adolescents from the same sample (Branje, Van Lieshout, \& Van Aken, 2004). We used aggregates of self-reports and other-reports to create personality scores and found decreases in Agreeableness and increases in Conscientiousness for mothers, decreases in younger siblings' Emotional Stability, and increases in older siblings' Openness to Experience. That study, however, focused on the relations between changes of different family members, and, therefore, age differences among adolescents and parents were neglected, which prevented conclusions regarding age-related personality development. For example, mothers ranged in age from 34 to 51 years at the first measurement wave, and therefore the personality changes across the two-year period of the study cannot be attributed to age changes. An accelerated or cohort-sequential longitudinal design as is used in the current study combines the advantages of both cross-sectional and longitudinal methods and divides mothers with similar ages at the first measurement wave into separate groups. Therefore, this design allows for conclusions regarding age-related personality development within individuals and variation between them (Farrington, 1991). 
Studies on personality development usually focus on self-reported personality. We will examine developmental changes in both self-reported personality and personality reported by other family members and examine if there are differences in personality development depending on the source of information. There are important differences between selfperceptions and perceptions by others. The self has greater access to self-relevant information than others do, and different personality-relevant information may be available to the self than to others (John \& Robins, 1993). Agreement between self-reports and otherreports is generally higher for personality factors with higher observability (Funder, 1995), trait relevance, self-reported consistency (Zuckerman et al., 1988), situational relevance (Funder \& Colvin, 1991) and social desirability (Funder \& Dobroth, 1987). Further, selfperceptions may be more influenced by motivational factors than other-perceptions (Funder \& Colvin, 1997), especially for more desirable or less desirable traits as compared to neutral traits. Extraversion and Conscientiousness are highly visible factors, whereas Emotional Stability is more difficult to observe (Borkenau \& Liebler, 1992; Kenny, Albright, Malloy, \& Kashy, 1994). Extraversion has been found to be the least evaluative trait and Openness the most evaluative trait (John \& Robins, 1993).

As several studies have shown that personality development is possible across the life span (Roberts, Walton, \& Viechtbauer, 2006a), attention needs to be directed to the causes of personality change (Roberts, Walton, \& Viechtbauer, 2006b; Terracciano, McCrae, Brant, \& Costa, 2005). Most studies have neglected interindividual differences in personality development. An important advantage of latent growth curve modelling is that it assesses both mean level development and interindividual differences in this development (Biesanz, West, \& Kwok, 2003), and factors affecting these interindividual differences can be examined. We will examine the influence of environmental factors on individual differences in personality development as emphasized in a contextual approach to personality (Caspi, Roberts, \& Shiner, 2005; Fraley \& Roberts, 2005; Lewis, 1999). We will focus on effects of support from a spouse or parent, significant life events, and pubertal development.

In sum, we will examine mean level personality development and interindividual differences in this development during adolescence and middle adulthood. We will examine developmental trajectories of personality and interindividual differences between these trajectories separately for the two sexes and for self-reports and reports by other family members to see whether gender and reporter moderate personality development. Finally, we will explore which factors can explain individual differences in personality development.

\section{METHOD}

\section{Participants}

Participants were 288 middle-class 2-parent Dutch families with at least two adolescent children from the Nijmegen Family and Personality Study (Haselager \& Van Aken, 1999). A representative selection of 23 municipalities throughout the Netherlands provided lists of families with at least two adolescents between the ages of 11 and 15 years. After a mail announcing the study, interviewers invited the two parents and two target adolescents from each family to participate until the required number of participants was attained. Of families contacted, 50\% agreed to participate in the study. Some frequent reasons for not 
participating were a lack of interest in the topic of the project, or a family member not wanting to cooperate. The average ages for the fathers and mothers were 43.9 and 41.7 years (ranging from 34.0 to 56.1 years and from 34.0 to 51.2 years, respectively). The older adolescents (144 boys, 144 girls) were 14.5 years of age on average (ranging from 11.4 to 16.0 years); the younger adolescents ( 136 boys, 152 girls) were 12.4 years of age on average (ranging from 11.0 to 14.8 years). To deal with the interdependency of judgements of older and younger adolescents in the same family, half of the older adolescents and half of the younger adolescents were randomly selected, resulting in a sample of 142 boys and 146 girls.

\section{Procedure}

Families participated in three annual measurement waves. In each wave, an interviewer visited the families at home and asked the mother, the father, and each of the two target adolescents to simultaneously complete a questionnaire. The presence of the interviewer encouraged complete responding and prevented collaboration among the family members. The adolescents evaluated their own personality and the personality of the father, the mother, and the other sibling; the parents evaluated their own personality and the personality of their partner, the older adolescent, and the younger adolescent. In each measurement wave, the two adolescents in the family were given a $\mathrm{CD}$ gift certificate after completion of the questionnaire. Following the completion of the third wave of measurement families who had participated at all 3 times were eligible for 5 lottery prizes. Attrition rate was very low: of the 288 families that started in the study, 285 participated in wave 3.

\section{Measures}

\section{Big Five personality dimensions}

A Dutch adaptation of 30 adjective Big-Five personality markers selected from Goldberg (1992) was used to have family members judge their own personalities and the personalities of the other three participating family members. The participants rated the 30 adjectives along a seven-point Likert scale ranging from (1) very untrue of this person to (4) sometimes untrue, sometimes true of this person to (7) very true of this person. Five personality dimensions were rated: Extraversion, Agreeableness, Conscientiousness, Emotional Stability and Openness to Experience. Extraversion assesses the extent to which the person actively engages the world or avoids intense (social) experience (e.g. talkative). Agreeableness assesses the interpersonal nature of the person and can range from warm and committed to others versus antagonistic (e.g. friendly). Conscientiousness assesses the degree of organization, persistence and motivation during the fulfilment of goal-directed task behaviours (e.g. meticulous). Emotional Stability assesses the regulation of emotions or the extent to which the person is emotionally stable or plagued by unpleasant experiences and distressing emotions (e.g. nervous). Openness to Experience assesses the depth, complexity and quality of a person's mental and experiential life, tolerance for and exploration of the unfamiliar, along with the flexibility of information processing (e.g. versatile). The internal consistencies (Cronbach's alpha) for the different personality dimensions rated by different family members ranged from 0.81 to 0.92 for judgements of fathers' personality, from 0.76 to 0.93 for judgements of mothers' personality, from 0.68 to 0.90 for judgements of older adolescents' personality, and from 0.63 to 0.87 for judgements of younger adolescents' personality. Correlations between self-reported and other-reported 
Table 1. Correlations between self-reported and other-reported personality factors

\begin{tabular}{lcccc}
\hline Big Five factor & Fathers & Mothers & Boys & Girls \\
\hline $\begin{array}{lllll}\text { Extraversion } \\
\text { Wave 1 }\end{array}$ & 0.44 & 0.48 & 0.38 & 0.59 \\
$\quad$ Wave 2 & 0.51 & 0.43 & 0.37 & 0.57 \\
$\quad$ Wave 3 & 0.51 & 0.51 & 0.37 & 0.46 \\
Agreeableness & & & & \\
$\quad$ Wave 1 & 0.13 & 0.19 & 0.19 & 0.34 \\
$\quad$ Wave 2 & 0.10 & 0.24 & 0.29 & 0.34 \\
$\quad$ Wave 3 & 0.19 & 0.24 & 0.22 & 0.45 \\
Conscientiousness & & & & \\
$\quad$ Wave 1 & 0.52 & 0.56 & 0.51 & 0.62 \\
$\quad$ Wave 2 & 0.61 & 0.54 & 0.49 & 0.58 \\
$\quad$ Wave 3 & 0.60 & 0.55 & 0.54 & 0.63 \\
Emotional stability & & & & \\
$\quad$ Wave 1 & 0.40 & 0.44 & 0.28 & 0.34 \\
$\quad$ Wave 2 & 0.45 & 0.44 & 0.25 & 0.34 \\
$\quad$ Wave 3 & 0.40 & 0.41 & 0.30 & 0.35 \\
Openness to experience & & & & \\
$\quad$ Wave 1 & 0.46 & 0.45 & 0.47 & 0.39 \\
$\quad$ Wave 2 & 0.45 & 0.52 & 0.43 & 0.41 \\
$\quad$ Wave 3 & 0.43 & 0.46 & 0.38 & 0.42 \\
\hline
\end{tabular}

Note. All correlations significant at $p<0.01$.

personality factors are displayed in Table 1 . These correlations show that convergent validity is adequate, only the correlations for different reports of Agreeableness were less strong.

\section{Perceived support}

Perceived marital/maternal support was measured with the Relational Support Inventory (RSI, Scholte, van Lieshout, \& van Aken, 2001). The inventory involves 24 items measured along a five-point Likert-scale ranging from very untrue of this person(1) to sometimes untrue, sometimes true of this person (3) to very true of this person (5). The questionnaire includes questions on the quality of information provided (e.g. 'This person explains or shows how I can make or do something'.), the respect for autonomy of the relationship partner (e.g. 'This person lets me solve problems as much as possible on my own but also provides help when I ask for it'.), the emotional support provided (e.g. 'In this person's view, I can't do anything right: he/she is always criticizing me'), and the convergence of goals (e.g. 'This person and I have many conflicts with regard to school achievement, the future, or career opportunities'). An overall support score for each of the family relationships was computed by averaging the scores on the 24 items. Reliabilities of these support scores ranged from $\alpha=0.80$ to $\alpha=0.87$.

\section{Life events}

Life events were assessed in the second measurement wave by asking fathers and mothers whether any of 15 events had happened to the family during the previous year. Events included were for example: 'Has one of your relatives died during the last year?' or 'Has your child changed school during the last year?' There was also room to report events not listed in the questionnaire. When an event had occurred, parents also reported the influence of the event on the children (negative, no, or positive). Scores were computed for total number of events, number of negative events and number of positive events. 


\section{Perceived pubertal timing}

Perceived pubertal timing was measured in the second measurement wave with the Pubertal Development Scale (PDS, Petersen, Crockett, Richards, \& Boxer, 1988). The PDS is a self report measure of pubertal status that assesses the physical changes associated with pubertal development including height, body hair growth, and skin changes, voice change and facial hair growth in boys, and breast development and menarche in girls. The PDS has shown adequate reliability and validity (Petersen et al., 1988). Perceived pubertal timing is assessed with the question: 'Do you think your physical development is any earlier or later than most other boys/girls your age?' Items were answered on a five-point scale, from 'much earlier' to 'much later'. Scores are recoded into early maturing, on time maturing, and late maturing.

\section{RESULTS}

\section{Development of big five personality characteristics}

Latent growth curve modelling (LGM) was used to examine changes in personality of adolescents, fathers and mothers. LGM is a flexible technique that can be used to model longitudinal change in repeated measures of variables (Duncan, Duncan, \& Strycker, 2001; Mehta \& West, 2000; Raudenbush \& Chan, 1993). The focus in latent growth curve analysis is on unobserved latent factors that are thought to represent the growth trajectories giving rise to the repeated measures over time, while controlling for the effects of measurement error.

Using an accelerated longitudinal design (Duncan, Duncan, \& Strycker, 2001), univariate latent growth curve models were fitted to the self- and other-reported Big Five personality characteristics of adolescent boys, girls, fathers and mothers separately to determine the form of the growth trajectory that most adequately described the change trajectories in personality during adolescence and adulthood (AMOS5, Arbuckle \& Wothke, 1999). In multigroup LGMs with the different cohorts of adolescents, fathers and mothers as the different groups, we estimated both linear and curvilinear changes in personality. Table 2 shows the number of individuals in the different cohorts of adolescents, fathers and mothers included in the analyses. For adolescents 5-group LGMs were

Table 2. Cohorts used in accelerated longitudinal design

\begin{tabular}{lccccccccccccccc}
\hline Adolescents & & & & & & & & & & & & & \\
$\quad$ Age & 11 & 12 & 13 & 14 & 15 & Total & & & & & & & & \\
N Boys & 29 & 27 & 28 & 28 & 30 & 142 & & & & & & & \\
N Girls & 29 & 31 & 29 & 29 & 28 & 146 & & & & & & & \\
$\quad$ N Total & 58 & 58 & 57 & 57 & 58 & 288 & & & & & & & & \\
$\quad \begin{array}{l}\text { Fathers } \\
\quad\end{array}$ & & & & & & & & & & & & & & \\
$\quad$ Age & 238 & 39 & 40 & 41 & 42 & 43 & 44 & 45 & 46 & 47 & 48 & 49 & $\geq 50$ & Total \\
N & 16 & 29 & 29 & 27 & 29 & 27 & 28 & 21 & 11 & 18 & 15 & 13 & 285 \\
Mothers & & & & & & & & & & & & & & \\
$\quad$ Age & $\leq 36$ & 37 & 38 & 39 & 40 & 41 & 42 & 43 & 44 & 45 & 46 & $\geq 47$ & Total & \\
N & 14 & 20 & 28 & 30 & 43 & 41 & 32 & 21 & 14 & 7 & 13 & 22 & 285 & \\
\hline
\end{tabular}




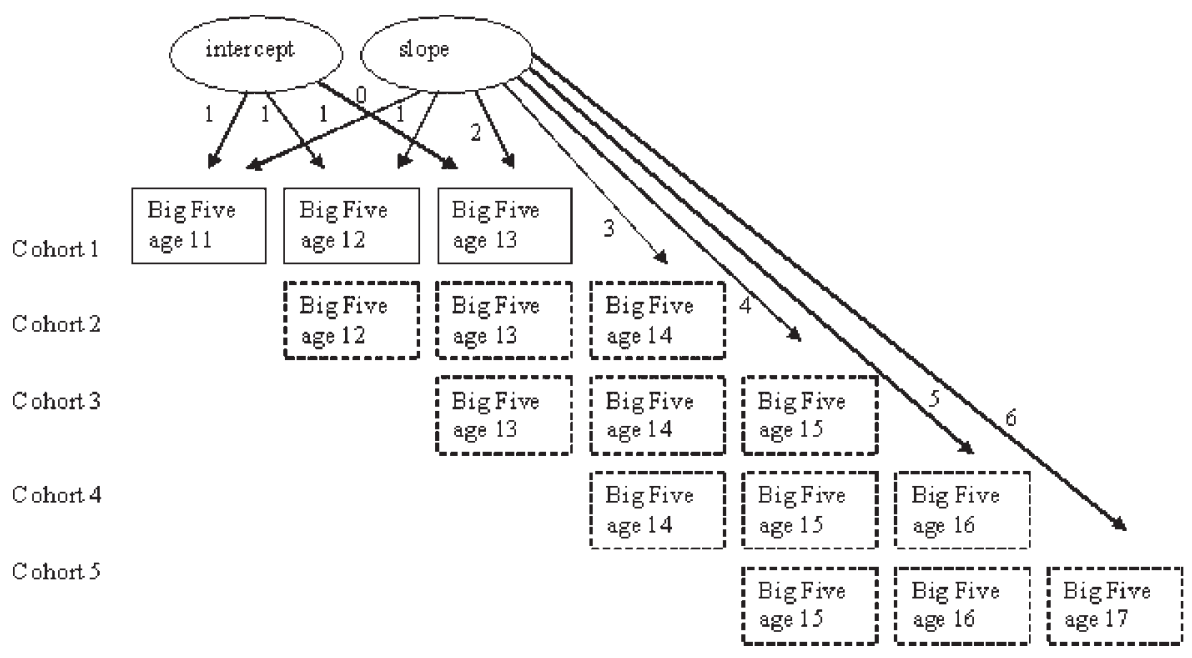

Figure 1. Accelerated linear latent growth curve model (example for adolescents).

estimated, for fathers 13-group LGMs, and for mothers 12-group LGMs. Figure 1 shows an example of how these different cohorts were used in the accelerated latent growth curve model. Using the different cohorts as different groups in the LGMs enabled to estimate changes in personality from 11 to 17 years of age for adolescent boys and girls, from 38 to 50 years of age for fathers and from 36 to 47 years of age for mothers.

Chi-square difference tests were used to evaluate whether the linear or curvilinear change trajectory provided the best fit to the data. The parameter estimates and the fit indices for these models are presented in Table 3 for self-reported personality characteristics, and in Table 4 for other-reported personality characteristics. Only the results for the best fitting models are presented. The fit indices show that these models provided an acceptable to good fit to the data, except for mothers' other-reported Agreeableness and Conscientiousness.

The significant mean estimates for the intercepts (Intercept M, Table 3 and 4) only indicate that the initial mean scores on Big Five factors significantly differed from zero. The variance for the intercept factors (Intercept $\sigma^{2}$ ) was significantly different from zero, which indicates that there were systematic individual differences in individuals' initial (T1) personality characteristics.

The slope mean estimates for each of the Big Five factors across the five age groups showed whether mean-level change in personality occurred over time. Overall, the Big Five factors Extraversion, Agreeableness, Conscientiousness and Openness to Experience of adolescents (i.e. boys and girls combined) revealed significant changes from 11 to 17 years of age. Considering self- and other-reports for boys and girls required some further specification of developmental trajectories (see Figures 2 and 3). Self-reported and otherreported Extraversion revealed a linear decrease for boys. Self-reported Extraversion showed a curvilinear pattern for girls with an increase followed by a decrease. Otherreported Extraversion for girls linearly increased. Self-reported Agreeableness linearly increased for girls but not for boys, and other-reported Agreeableness did not reveal significant changes over time. Self-reported and other-reported Conscientiousness linearly increased for girls only. No significant changes were found for Emotional Stability. 
Table 3. Latent growth curve results for self-reported Big Five personality characteristics of family members

\begin{tabular}{|c|c|c|c|c|c|c|c|c|}
\hline \multirow[b]{2}{*}{ Big Five factor } & \multicolumn{2}{|c|}{ Intercepts } & \multicolumn{2}{|c|}{ Slopes } & \multicolumn{4}{|c|}{ Fit indices } \\
\hline & Mean & $\sigma^{2}$ & Mean & $\sigma^{2}$ & $X^{2}$ & Df & RMSEA & CFI \\
\hline \multicolumn{9}{|l|}{ Extraversion } \\
\hline Fathers curvelinear & $4.64^{* *}$ & $1.04^{* *}$ & -0.14 & $0.44^{* * *}$ & 95.36 & 74 & 0.03 & 0.97 \\
\hline Mothers curvelinear & $4.72^{* *}$ & $1.81^{* *}$ & 0.10 & 0.31 & 72.63 & 67 & 0.02 & 0.99 \\
\hline Adolescents linear & $5.12^{* *}$ & $0.38^{* *}$ & $-0.29^{*}$ & 0.32 & 31.61 & 25 & 0.03 & 0.98 \\
\hline Boys linear & $5.16^{* *}$ & 0.02 & $-0.49^{*}$ & 0.12 & 22.39 & 25 & 0.00 & 1 \\
\hline Girls curvelinear & $4.87^{* *}$ & $0.96^{* *}$ & $0.27^{*}$ & 0.60 & 36.03 & 25 & 0.06 & 0.95 \\
\hline \multicolumn{9}{|l|}{ Agreeableness } \\
\hline Fathers linear & $5.57^{* *}$ & $0.24^{* *}$ & -0.07 & $0.20^{* * *}$ & 81.19 & 74 & 0.02 & 0.98 \\
\hline Mothers linear & $5.76^{* *}$ & $0.23^{* *}$ & $-0.18^{* * *}$ & 0.00 & 95.26 & 69 & 0.04 & 0.93 \\
\hline Adolescents linear & $5.39^{* *}$ & $0.44^{* *}$ & $0.27^{* *}$ & $0.54^{* * *}$ & 40.99 & 25 & 0.05 & 0.93 \\
\hline Boys curvelinear & $5.46^{* *}$ & $0.52^{* *}$ & -0.05 & $0.94^{* *}$ & 38.57 & 25 & 0.06 & 0.88 \\
\hline Girls linear & $5.48^{* *}$ & $0.36^{\text {** }}$ & $0.30^{* *}$ & 0.29 & 45.72 & 27 & 0.08 & 0.82 \\
\hline \multicolumn{9}{|l|}{ Conscientiousness } \\
\hline Fathers linear & $5.04^{* *}$ & $0.64^{* *}$ & 0.09 & $0.72^{*}$ & 91.72 & 74 & 0.03 & 0.97 \\
\hline Mothers linear & $5.25^{* *}$ & $0.80^{* *}$ & -0.10 & 0.29 & 79.59 & 68 & 0.02 & 0.98 \\
\hline Adolescents linear & $4.22^{* *}$ & $0.86^{* *}$ & $0.30^{*}$ & 0.12 & 31.60 & 26 & 0.03 & 0.99 \\
\hline Boys linear & $4.22^{* *}$ & $0.80^{* *}$ & 0.12 & 0.01 & 32.41 & 26 & 0.04 & 0.96 \\
\hline Girls linear & $4.21^{\text {** }}$ & $0.90^{* *}$ & $0.56^{* *}$ & 0.23 & 29.95 & 26 & 0.03 & 0.98 \\
\hline \multicolumn{9}{|l|}{ Emotional stability } \\
\hline Fathers curvelinear & $4.75^{* *}$ & $0.68^{* *}$ & -0.11 & $0.44^{*}$ & 78.39 & 74 & 0.01 & 0.99 \\
\hline Mothers linear & $4.02^{* *}$ & $0.88^{* *}$ & $0.42^{*}$ & 0.00 & 67.67 & 69 & 0.00 & 1 \\
\hline Adolescents linear & $4.56^{* *}$ & $0.45^{* *}$ & -0.14 & 0.86 & 39.67 & 25 & 0.05 & 0.94 \\
\hline Boys linear & $4.61^{* *}$ & $0.37^{* *}$ & -0.17 & $0.69^{*}$ & 35.14 & 26 & 0.05 & 0.91 \\
\hline Girls linear & $4.54^{* *}$ & $0.44^{*}$ & -0.13 & 0.81 & 31.65 & 25 & 0.04 & 0.95 \\
\hline \multicolumn{9}{|l|}{ Openness to experience } \\
\hline Fathers linear & $4.94^{* *}$ & $0.80^{* *}$ & -0.26 & 0.00 & 81.12 & 75 & 0.02 & 0.99 \\
\hline Mothers curvelinear & $4.44^{* *}$ & $1.08^{* *}$ & $0.17^{* * *}$ & 0.35 & 71.11 & 67 & 0.02 & 0.99 \\
\hline Adolescents linear & $4.75^{* *}$ & $0.49^{* *}$ & $0.32^{* *}$ & 0.16 & 43.94 & 26 & 0.05 & 0.95 \\
\hline Boys curvelinear & $4.93^{* *}$ & $0.80^{* *}$ & 0.06 & $1.01^{* *}$ & 41.36 & 25 & 0.07 & 0.91 \\
\hline Girls linear & $4.71^{* *}$ & $0.50^{* *}$ & $0.36^{*}$ & 0.02 & 46.19 & 26 & 0.07 & 0.88 \\
\hline
\end{tabular}

Whereas self-reported Openness linearly increased girls, other-reported Openness linearly decreased for boys.

Significant variance in growth trajectories was found more often for boys than for girls. Significant individual differences in change in Agreeableness, Conscientiousness, Emotional Stability and Openness to Experience were found. For boys' self-reported Agreeableness, significant individual differences in curvilinear change were found with some boys showing a decrease followed by an increase and other boys showing no changes. For boys' other-reported Conscientiousness, significant individual differences in curvilinear change were found with some boys showing an increase followed by a decrease and other boys showing no changes. Variation in the extent to which boys linearly decreased in Emotional Stability was found for boys' self-reports. Variance in change in Openness to Experience were found for self-reports of boys and other-reports of adolescents: boys 
Table 4. Latent growth curve results for other-reported Big Five personality characteristics of family members

\begin{tabular}{|c|c|c|c|c|c|c|c|c|}
\hline \multirow[b]{2}{*}{ Big Five factor } & \multicolumn{2}{|c|}{ Intercepts } & \multicolumn{2}{|c|}{ Slopes } & \multicolumn{4}{|c|}{ Fit indices } \\
\hline & M & $\sigma^{2}$ & M & $\sigma^{2}$ & $X^{2}$ & $\mathrm{df}$ & RMSEA & CFI \\
\hline \multicolumn{9}{|l|}{ Extraversion } \\
\hline Fathers linear & $5.23^{* *}$ & $0.49^{* *}$ & $-0.39^{* *}$ & 0.12 & 104.02 & 74 & 0.04 & 0.95 \\
\hline Mothers curvelinear & $5.18^{* *}$ & $0.27^{* *}$ & 0.13 & 0.14 & 96.22 & 67 & 0.04 & 0.93 \\
\hline Adolescents curvelinear & $5.03^{* *}$ & $0.50^{* *}$ & $-0.11^{* * *}$ & 0.05 & 21.01 & 25 & 0.00 & 1 \\
\hline Boys linear & $5.02^{* *}$ & $0.64^{* *}$ & $-0.30^{*}$ & 0.01 & 29.18 & 26 & 0.03 & 0.99 \\
\hline Girls linear & $4.91^{* *}$ & $0.53^{* *}$ & $0.31^{*}$ & 0.00 & 32.21 & 27 & 0.04 & 0.98 \\
\hline \multicolumn{9}{|l|}{ Agreeableness } \\
\hline Fathers curvelinear & $5.79^{* *}$ & $0.15^{* *}$ & $-0.17^{*}$ & 0.13 & 82.34 & 73 & 0.02 & 0.98 \\
\hline Mothers curvelinear & $5.90^{* *}$ & $0.18^{* *}$ & -0.08 & 0.01 & 130.66 & 68 & 0.06 & 0.77 \\
\hline Adolescents linear & $5.54^{* *}$ & $0.23^{* *}$ & -0.07 & 0.09 & 28.32 & 26 & 0.02 & 0.99 \\
\hline Boys linear & $5.49^{* *}$ & $0.24^{* *}$ & -0.15 & 0.15 & 29.84 & 26 & 0.03 & 0.98 \\
\hline Girls linear & $5.59^{* *}$ & $0.20^{* *}$ & 0.01 & 0.01 & 27.15 & 26 & 0.02 & 0.99 \\
\hline \multicolumn{9}{|l|}{ Conscientiousness } \\
\hline Fathers linear & $4.86^{* *}$ & $0.60^{* *}$ & 0.22 & $0.40^{* * *}$ & 99.37 & 74 & 0.04 & 0.96 \\
\hline Mothers linear & $4.98^{* *}$ & $0.35^{* *}$ & $0.44^{* *}$ & 0.24 & 258.74 & 68 & 0.10 & 0.54 \\
\hline Adolescents curvelinear & $4.03^{* *}$ & $1.02^{* *}$ & 0.00 & $0.85^{* *}$ & 24.32 & 25 & 0.00 & 1 \\
\hline Boys curvelinear & $3.79^{* *}$ & $0.87^{* *}$ & 0.06 & $0.87^{* *}$ & 14.19 & 25 & 0.00 & 1 \\
\hline Girls linear & $4.02^{* *}$ & $0.82^{* *}$ & $0.44^{* *}$ & 0.26 & 35.20 & 26 & 0.05 & 0.98 \\
\hline \multicolumn{9}{|l|}{ Emotional Stability } \\
\hline Fathers linear & $4.99^{* *}$ & $0.34^{* *}$ & $-0.28^{*}$ & 0.00 & 95.56 & 74 & 0.03 & 0.95 \\
\hline Mothers curvelinear & $4.32^{* *}$ & $0.47^{* *}$ & 0.16 & 0.48 & 102.54 & 67 & 0.04 & 0.92 \\
\hline Adolescents curvelinear & $4.60^{* *}$ & $0.50^{* *}$ & 0.03 & 0.02 & 31.03 & 25 & 0.03 & 0.99 \\
\hline Boys linear & $4.68^{* *}$ & $0.34^{* *}$ & -0.02 & 0.04 & 35.20 & 26 & 0.05 & 0.95 \\
\hline Girls linear & $4.51^{* *}$ & $0.54^{* *}$ & 0.12 & $0.95^{*}$ & 21.45 & 25 & 0.00 & 1 \\
\hline \multicolumn{9}{|l|}{ Openness to Experience } \\
\hline Fathers linear & $4.53^{* *}$ & $0.44^{* *}$ & 0.11 & $0.30^{* * *}$ & 104.32 & 74 & 0.04 & 0.96 \\
\hline Mothers curvelinear & $4.72^{* *}$ & $0.45^{* *}$ & $0.14^{* * *}$ & 0.35 & 89.89 & 67 & 0.04 & 0.95 \\
\hline Adolescents linear & $4.93^{* *}$ & $0.44^{* *}$ & -0.09 & $0.67^{*}$ & 24.88 & 25 & 0.00 & 1 \\
\hline Boys linear & $4.92^{* *}$ & $0.43^{* *}$ & $-0.28^{*}$ & 0.54 & 20.95 & 25 & 0.00 & 1 \\
\hline Girls curvelinear & $5.07^{* *}$ & $0.50^{* *}$ & -0.11 & $0.31^{* * *}$ & 26.88 & 25 & 0.02 & 0.99 \\
\hline
\end{tabular}

differed in the extent to which they increased and subsequently decreased, and adolescents differed in the extent to which they linearly decreased. Girls significantly differed in the extent to which they revealed other-reported linear increases in Emotional Stability.

Only some personality factors were found to change during adulthood (see Figure 4). For fathers, mean decreases were found for other-reports of Extraversion, Agreeableness and Emotional Stability. For mothers self-reported Emotional Stability and other-reported Conscientiousness significantly increased with age. Both self-reported and other-reported Agreeableness tended to decrease, but this decrease was only marginally significant. Significant individual differences in change were found only for fathers for self-reported Conscientiousness and Emotional Stability: fathers differed in the extent to which they changed in Conscientiousness and Emotional Stability. 


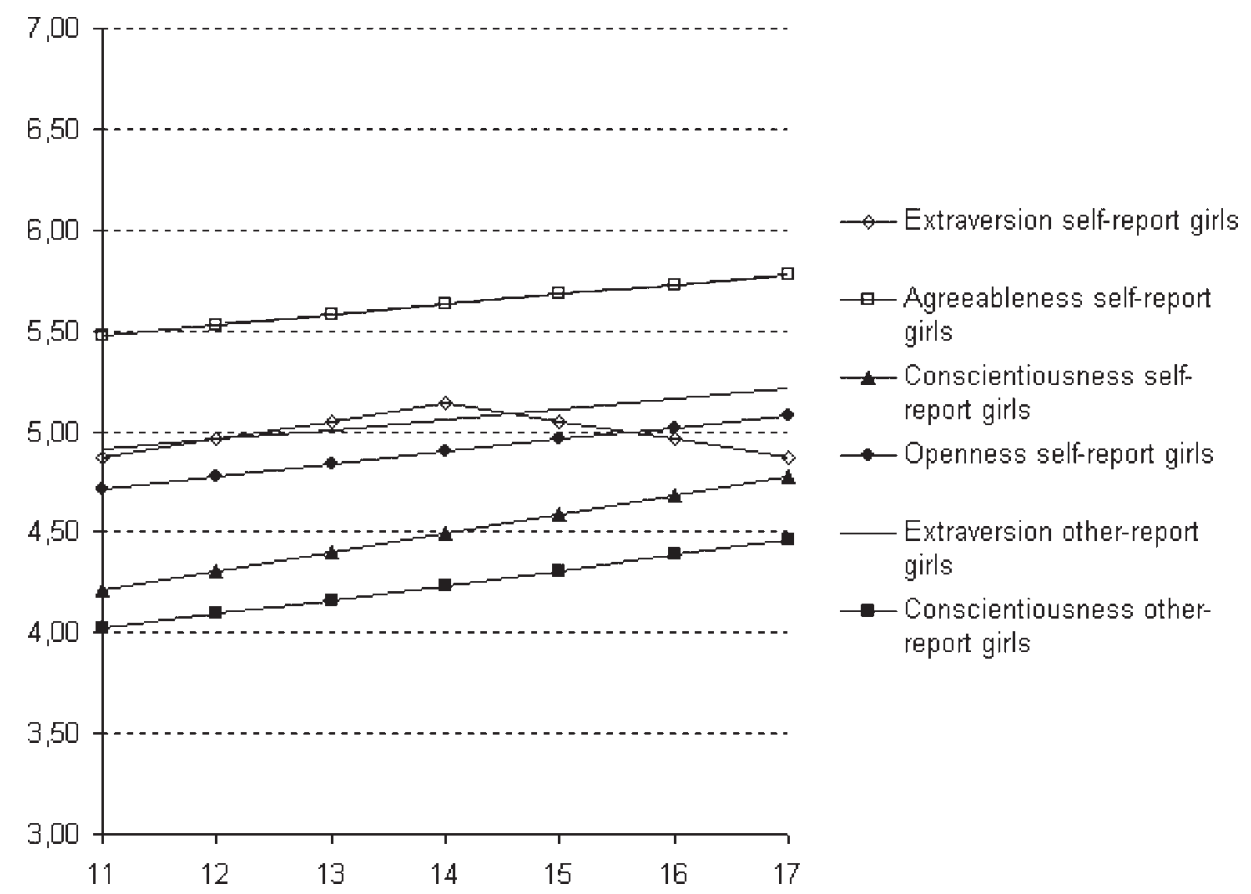

Figure 2. Personality development for adolescent girls.

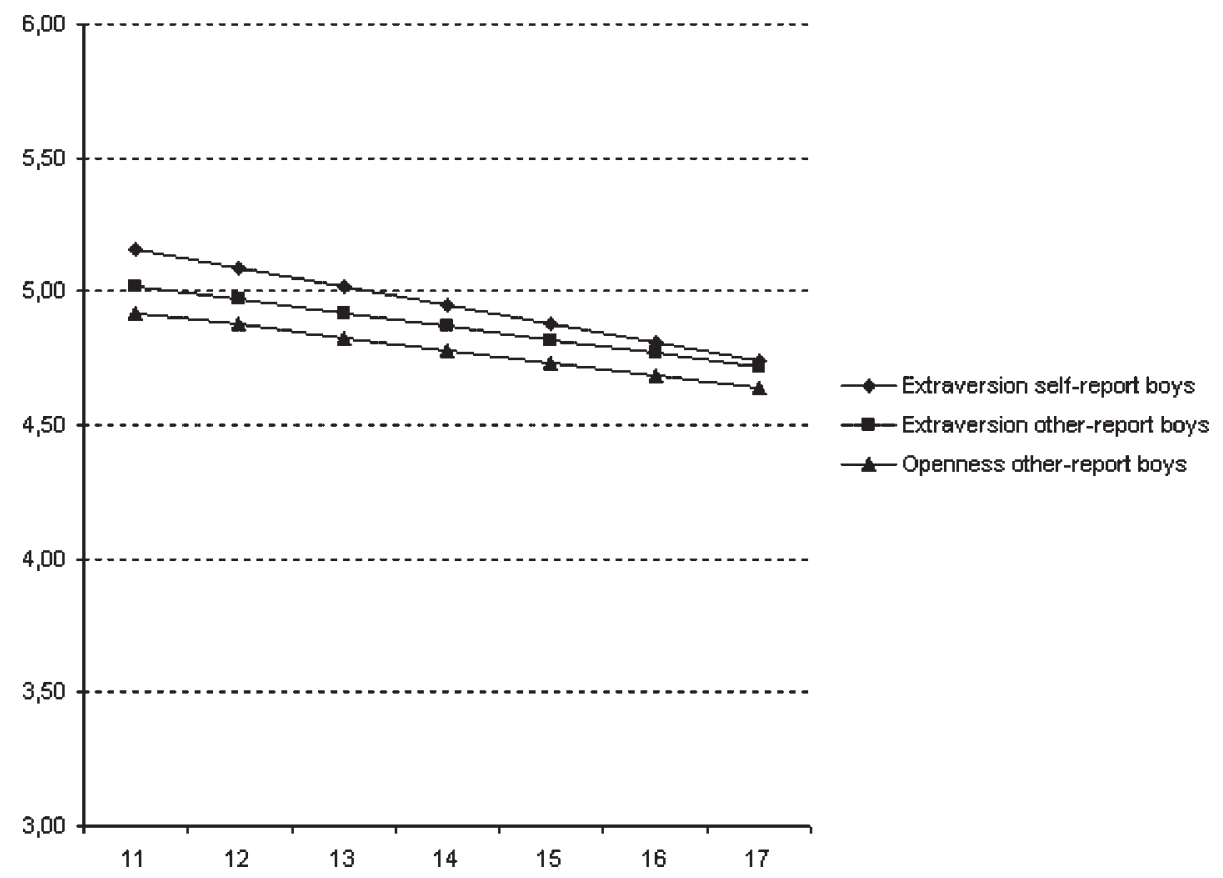

Figure 3. Personality development for adolescent boys. 


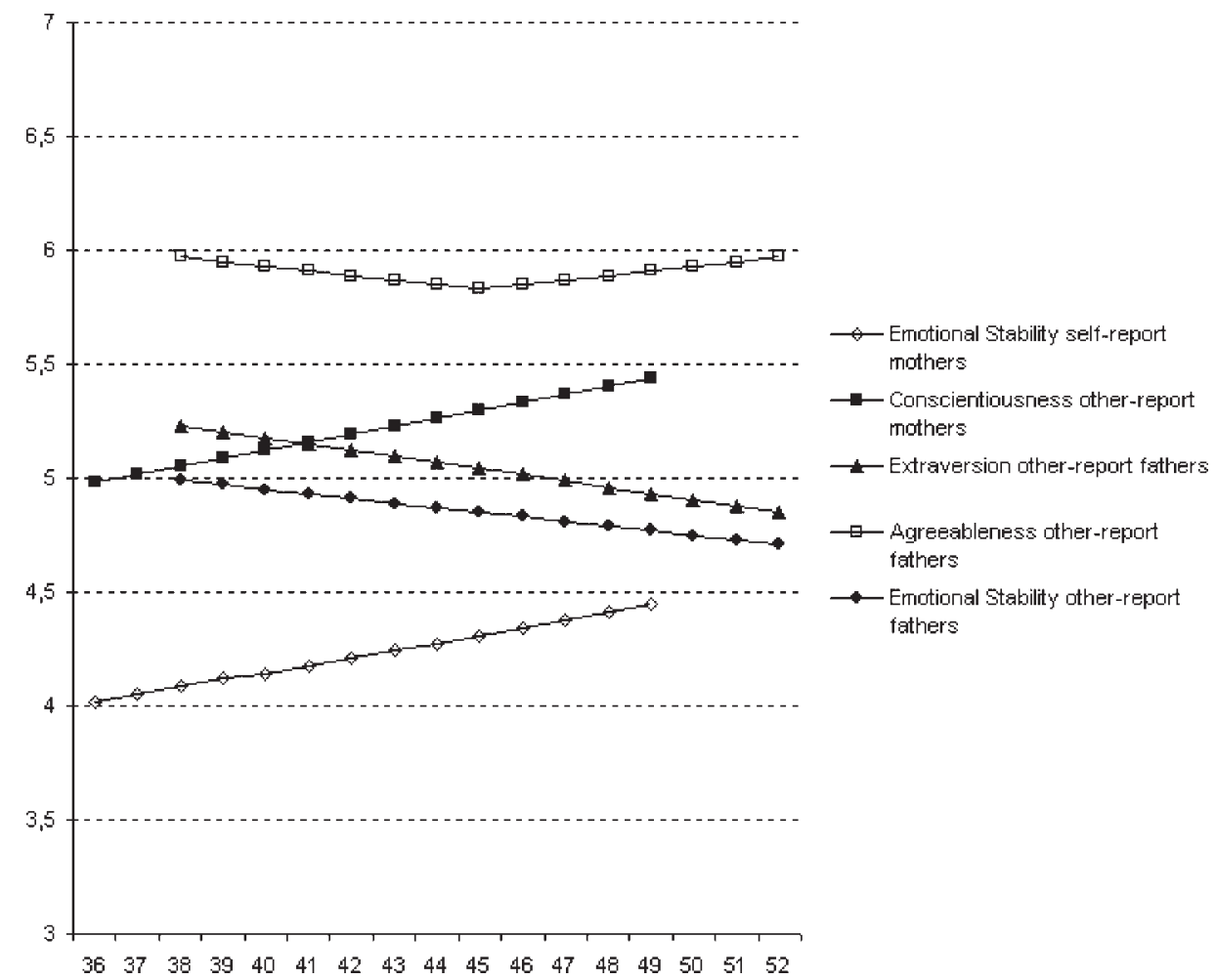

Figure 4. Personality development for adults.

\section{Predicting interindividual differences in personality development}

We performed additional analyses to explore the potential contribution of several moderators to variance in personality change. When significant interindividual differences in change were found for a personality factor of a particular family member, several predictors were related to slope variances, thereby controlling for the relation of these predictors to intercept variance. Significant slope variances for children were predicted by maternal support, pubertal timing, number of life events, number of positive life events, and number of negative life events. We predicted significant slope variances of fathers by support from marital partner, number of life events, number of positive life events, and number of negative life events reported for their children. The results showed that none of these factors significantly predicted individual differences in personality development (see Table 5).

\section{DISCUSSION}

The goal of the present study was to examine development of personality across adolescence and an extended period of adulthood. By estimating growth curves for adolescents from 11 to 17 years of age and for adult males aged 38 to 52 years and women 
Table 5. Predictors of individual differences in personality development

\begin{tabular}{lccccc}
\hline Predictor & $\begin{array}{l}\text { Marital/maternal } \\
\text { support }\end{array}$ & $\begin{array}{l}\text { Pubertal } \\
\text { timing }\end{array}$ & $\begin{array}{l}\text { Number of } \\
\text { life events }\end{array}$ & $\begin{array}{l}\text { Positive } \\
\text { life events }\end{array}$ & $\begin{array}{c}\text { Negative } \\
\text { life events }\end{array}$ \\
\hline $\begin{array}{l}\text { Boys' other-reported } \\
\begin{array}{l}\text { Conscientiousness } \\
\text { Boys' self-reported }\end{array}\end{array}$ & 0.01 & 0.02 & 0.09 & 0.11 & 0.00 \\
$\begin{array}{l}\text { Agreeableness } \\
\text { Boys' self-reported }\end{array}$ & 0.05 & 0.07 & 0.17 & 0.15 & 0.20 \\
$\begin{array}{l}\text { Emotional Stability } \\
\text { Boys' self-reported }\end{array}$ & 0.07 & 0.08 & 0.14 & 0.16 & 0.10 \\
$\begin{array}{l}\text { Openness } \\
\text { Girls' other-reported }\end{array}$ & 0.01 & 0.00 & 0.10 & 0.06 & 0.31 \\
$\begin{array}{l}\text { Emotional stability } \\
\text { Fathers' self-reported }\end{array}$ & 0.02 & -0.01 & 0.01 & 0.05 & -0.13 \\
$\begin{array}{l}\text { Conscientiousness } \\
\text { Fathers' self-reported }\end{array}$ & 0.04 & & 0.12 & & \\
Emotional stability & & & 0.15 & & \\
\hline
\end{tabular}

aged 36 to 49 years, we clearly demonstrated that personality develops, not only during adolescence but also across adulthood. Furthermore, there appeared to be interindividual differences in personality development.

Across adolescence, girls were found to change more often than boys. The expected increase in Openness was found for girls' self-reported Openness only. Girls also increased in self- and other-reported Conscientiousness and other-reported Agreeableness and Extraversion. Girls' self-reported Extraversion showed a curvelinear change pattern. In contrast, only three mean changes were found for boys: Other-reported Openness and both self- and other-reported Extraversion decreased for boys. These gender differences in personality development may be related to differences in cerebral cortical development. During early adolescence, girls undergo a faster acceleration in cerebral cortical development than boys and remain in advance of boys until 14-15 years (Andrich \& Styles, 1994; Colom \& Lynn, 2004). As a result, during early adolescence girls are generally about 2 years ahead of boys in intellectual and social-cognitive functioning (Silberman \& Snarey, 1993; Porteous, 1985). These differences might account for earlier development in personality of girls compared to boys, who may catch up with girls from 16 years onwards. The changes in personality may also be related to changes in social expectations regarding education and work or domestic chores. Because girls' pubertal development occurs earlier than boys (Paikoff \& Brooks-Gunn, 1991), they may look more mature and elicit greater expectations from others in these areas than boys.

Unexpectedly, we did not find change in Emotional Stability for girls, which might be due to the age range studied: Perhaps Emotional Stability is starting to change in late adolescence only. Also in contrast with our expectations, mean development in Extraversion was found during adolescence. Both self-reported and other-reported Extraversion decreased for boys. Whereas girls' self-reported Extraversion showed an increase followed by a decrease, girls' other-reported Extraversion increased over time. Further research should try to replicate and offer an explanation for this finding.

Mean personality development for parents was observed as well, confirming that personality development continues across the life-span. Most personality change of adults was found for other-reports. An expected decrease in Extraversion was found only for 
other-reports regarding fathers. The expected increase in Conscientiousness was found only for other-reports regarding mothers, and the expected increase in Emotional Stability was found only for mothers' self-reports. In fact, fathers' Emotional Stability as reported by others decreased with age. This increase in females' Emotional Stability is in agreement with earlier findings (Small, Hertzog, Hultsch, \& Dixon, 2003; Srivastava et al., 2003) and may be related to better emotion regulation as individuals get older (Gross et al., 1997).

Different personality factors were found to change for self-reports versus other-reports. Whereas for adolescents, self-reported personality changed more often than other-reported personality, for parents the opposite appeared. We only found agreement between self- and other-reports for girls' Conscientiousness and boys' Extraversion. These findings contrast with cross-sectional results of McCrae et al. (2004), who found that other-reported and self-reported personality characteristics generally changed in the same direction. As disagreement between self-reports and other-reports occurred across factors, these differences cannot be explained by differences in observability and evaluativeness of traits (cf. John \& Robins, 1993; Zuckerman et al., 1988). The lack of agreement may be due to differences in the situations in which individuals and their family members observe personality. Self-other agreement is largely depending on the observed situation (Borkenau, Mauer, Riemann, Spinath, \& Angleitner, 2004). Both the larger frequency of changes for adolescents' self-reports and the differences in direction of change may be related to their increasing participation in roles and functions outside the family, which might make them a better observer of their changing personality in these contexts than family members. Perhaps adolescents base their judgements of personality on situations with friends outside the family, and their family members base their judgements on family situations. For example, friendship relationships become increasingly intimate during adolescence, especially for girls, but relatives might not observe these intimate friendship interactions regularly, which results in self-reported but not other-reported increases in Agreeableness. Similarly, increased Openness may be mainly directed to new experiences outside family life and adolescents may be more and more reluctant to participate in family activities, leading to divergent perspectives of parents and adolescents concerning adolescents' Openness. The larger frequency of parents' changes in other-reported personality may be related to the changing perception that children have of their parents during adolescence. For example, they may appreciate more what mothers do for them as they get older, resulting in increasing perceptions of Conscientiousness.

An important strength of the current study is the focus on interindividual differences in mean personality change. Gender was found as an important moderator of personality change, both for adolescents and for adults, which is in agreement with earlier findings (Small et al., 2003; Mroczek \& Spiro, 2003). After controlling for gender, mean development in parental personality showed very little interindividual variability, suggesting that development of personality characteristics among females and males is due to normative intrinsic maturation (Costa \& McCrae, 2006). More interindividual differences in personality development were found for boys and fathers than for girls and mothers. These results indicate that there may be more individual differences in personality development for males than for females (Srivastava et al., 2003). Future research is needed to provide an explanation for these differences.

Age-related development in personality suggests that individuals are growing toward increasing maturity and adaptation. Cross-cultural comparisons showing comparable changes across different nations (McCrae et al., 1999, 2000, 2002) suggest this development to be normative and life-course related. Although our mean-level changes 
may support such life-course related developmental changes, the individual differences in personality development suggest different developmental trajectories that may be affected by historically and culturally determined environmental influences as emphasized in a contextual approach to personality (Lewis, 1999). Our results did not offer support for contextual influences on personality change, suggesting that we did not include the right factors. However, the use of an accelerated design with relatively small subgroups might have reduced power and have limited the possibilities to examine moderating variables. In other studies, significant life events or turning points have been linked to Big Five personality change (Vaidya et al., 2002; Mroczek \& Spiro, 2003). For example, Mroczek and Spiro found that men showed a faster increase in Emotional Stability after remarriage or death of a spouse. Also, using the same sample as the current study, Branje, van Lieshout, and van Aken (2004) found evidence for correlated changes between personality and perceptions of relational support, in particular for Agreeableness and Openness to Experience. Social and cultural changes between birth cohorts may also be an important influence on personality development. For example, since the last five decades, U.S. citizens have revealed increases in Extraversion and decreases in Emotional Stability (Twenge, 2000, 2001), and whereas older cohorts changed slower in Emotional Stability and decreased in Extraversion younger cohorts changed faster in Emotional Stability and increased in Extraversion (Mroczek \& Spiro, 2003). Future research should focus more directly on factors both within the individual and in the environment that can account for the development of personality. Such studies will offer valuable information about whether normative personality development is affected by intrinsic factors or by external factors such as social roles.

To conclude, by using data of family members participating in a short-term longitudinal study within an accelerated longitudinal design to estimate growth curves of personality development, we were able to examine personality development in adolescence from age 11 to 17 and in adulthood from approximately age 35 to 50. This design gives us greater confidence to have captured developmental personality changes within individuals compared to studies examining mean differences between different age groups. Of course, the study is limited by the restricted age ranges of the participants and the relatively small age groups. More extended longitudinal research is needed that follows individuals over an elongated period to capture life-span personality development from adolescence to late adulthood.

\section{REFERENCES}

Allik, J., Laidra, K., Realo, A., \& Pullmann, H. (2004). Personality development from 12 to 18 years of age: Changes in mean levels and structure of traits. European Journal of Personality, 18, 445462.

Andrich, D., \& Styles, I. (1994). Psychometric evidence of intellectual growth spurts in early adolescence. Journal of Early Adolescence, 14, 328-344.

Arbuckle, J. L., \& Wothke, W. (1999). Amos 4.0 User's Guide. Chacago: SmallWaters Corporation.

Asendorpf, J. B., \& Van Aken, M. A. G. (2003). Validity of Big Five personality judgments in childhood: A 9 year longitudinal study. European Journal of Personality, 17, 1-17.

Baltes, P. B. (1987). Theoretical propositions of life-span developmental psychology: On the dynamics between growth and decline. Developmental Psychology, 23, 611-626.

Biesanz, J. C., West, S. G., \& Kwok, O. M. (2003). Personality over time: Methodological approaches to the study of short-term and long-term development and change. Journal of Personality, 71, 905941. 
Borkenau, P., \& Liebler, A. (1992). Trait inferences: Sources of validity at zero acquaintance. Journal of Personality and Social Psychology, 62, 645-657.

Borkenau, P., Mauer, N., Riemann, R., Spinath, F. M., \& Angleitner, A. (2004). Thin slices of behavior as cues of personality and intelligence. Journal of Personality and Social Psychology, 86, 599-614.

Branje, S. J. T., van Lieshout, C. F. M., \& van Aken, M. A. G. (2004). Relations between Big Five personality characteristics and perceived support in adolescents' families. Journal of Personality and Social Psychology, 86, 615-628.

Caspi, A., Roberts, B. W., \& Shiner, R. L. (2005). Personality development: Stability and change. Annual Review of Psychology, 56, 453-484.

Colom, R., \& Lynn, R. (2004). Testing the developmental theory of sex differences in intelligence on 12-18 year olds. Personality and Individual Differences, 36, 75-82.

Costa, P. T., Jr., Herbst, J. H., McCrae, R. R., \& Siegler, I. C. (2000). Personality at midlife: Stability, intrinsic maturation, and response to life events. Assessment, 7, 365-378.

Costa, P. T., Jr., \& McCrae, R. R. (1988). Personality in adulthood: A six-year longitudinal study of self-reports and spouse ratings on the NEO Personality Inventory. Journal of Personality and Social Psychology, 54, 853-863.

Costa, P. T., Jr., \& McCrae, R. R. (1994). Stability and change in personality from adolescence through adulthood. In C. F. Halverson, G. A. Kohnstamm, \& R. P. Martin (Eds.), The developing structure of temperament and personality from infancy to adulthood (pp. 139-150). Hillsdale, NJ: Erlbaum.

Costa, P. T., Jr., \& McCrae, R. R. (1997). Longitudinal stability of adult personality. In R. Hogan, J. A. Johnson, \& S. R. Briggs (Eds.), Handbook of personality psychology (pp. 269-290). San Diego, CA, US: Academic Press.

Costa, P. T., Jr., \& McCrae, R. R. (2006). Age changes in personality and their origins: Comment on Roberts, Walton, and Viechtbauer (2006). Psychological Bulletin, 132, 26-28.

De Fruyt, F., Mervielde, I., Hoekstra, H. A., \& Rolland, J. P. (2000). Assessing adolescents' personality with the NEO PI-R. Assessment, 7, 329-345.

Duncan, S. C., Duncan, T. E., \& Strycker, L. A. (2001). Qualitative and quantitative shifts in adolescent problem behavior development: A cohort-sequential multivariate latent growth modeling approach. Journal of Psychopathology and Behavioral Assessment, 23, 43-50.

Farrington, D. P. (1991). Longitudinal research strategies: Advantages, problems, and prospects. Journal of American Academy of Child and Adolescent Psychiatry, 30, 369-374.

Fraley, C. R., \& Roberts, B. W. (2005). Patterns of continuity: A dynamic model for conceptualizing the stability of individual differences in psychological constructs across the life course. Psychological Review, 112, 60-74.

Funder, D. C. (1995). On the accuracy of personality judgment: A realistic approach. Psychological Review, 102, 652-670.

Funder, D. C., \& Colvin, C. R. (1991). Explorations in behavioral consistency: Properties of persons, situations, and behaviors. Journal of Personality and Social Psychology, 60, 773-794.

Funder, D. C., \& Colvin, C. R. (1997). Congruence of self and others' judgments of personality. In R. Hogan, J. A. Johnson, \& S. R. Briggs (Eds.), Handbook of personality psychology (pp. 617647). Orlando, FL: Academic Press.

Funder, D. C., \& Dobroth, K. M. (1987). Differences between traits: Properties associated with interjudge agreement. Journal of Personality and Social psychology, 52, 409-418.

Goldberg, L. R. (1990). An alternative 'description of personality': The Big-Five factor structure. Journal of Personality and Social Psychology, 59, 1216-1229.

Goldberg, L. R. (1992). The development of markers of the Big-Five factor structure. Psychological Assessment, 4, 26-42.

Gross, J. J., Carstensen, L. L., Pasupathi, M., Tsai, J., Goetestam-Skorpen, C., \& Hsu, A. Y. C. (1997). Emotion and aging: Experience, expression, and control. Psychology and Aging, 12, 590-599.

Haselager, G. J. T., \& Van Aken, M. A. G. (1999). Codebook of the research project Family and Personality: Vol. 1. First measurement wave. Nijmegen, The Netherlands: University of Nijmegen, Faculty of Social Science.

John, O. P., \& Robins, R. W. (1993). Determinants of interjudge agreement on personality traits: The Big Five domains, observability, evaluativeness, and the unique perspective of the self. Journal of Personality, 61, 521-551. 
Jones, C. J., Livson, N., \& Peskin, H. (2003). Longitudinal hierarchical linear modeling analyses of California Psychological Inventory data from age 33 to 75 : An examination of stability and change in adult personality. Journal of Personality Assessment, 80, 294-308.

Jones, C. J., \& Meredith, W. (1996). Patterns of personality change across the life span. Psychology and Aging, 11, 57-65.

Kenny, D. A., Albright, L., Malloy, T. E., \& Kashy, D. A. (1994). Consensus in interpersonal perception: Acquaintance and the Big Five. Psychological Bulletin, 116, 245-258.

Lewis, M. (1999). On the development of personality. In L. A. Pervin, \& O. P. John (Eds.), Handbook of personality: Theory and research (pp. 327-346). New York: Guilford.

McCrae, R. R., \& Costa, P. T. (1994). The stability of personality: Observation and evaluations. Current Directions in Psychological Science, 3, 173-175.

McCrae, R. R., Costa, P. T., Jr. (1997). Personality trait structure as a human universal. The American Psychologist, 52, 509-516.

McCrae, R. R., Costa, P. T., Jr. (1999). A Five-Factor theory of personality. In L. A. Pervin, \& O. P. John (Eds.), Handbook of personality: Theory and research (2nd ed., pp. 139-153). New York: Guilford.

McCrae, R. R., Costa, P. T., Jr., Hebíková, M., Urbánek, T., Martin, A. T., Oryol, V. E., Rukavishnikov, A. A., \& Senin, I. G. (2004). Age differences in personality traits across cultures: self-report and observer perspectives. European Journal of Personality, 18, 143-157.

McCrae, R. R., Costa, P. T., Jr., Ostendorpf, F., Angleitner, A., Hrebickova, M., Avia, M. D., Sanz, J., Sanchez-Bernardos, M. L., Kusdil, M. E., Woodfield, R., Saunders, P. R., \& Smith, P. B. (2000). Nature over nurture: Temperament, personality, and life span development. Journal of Personality and Social Psychology, 78, 173-186.

McCrae, R. R., Costa, P. T., Pedroso de Lima, M., Simoes, A., Ostendorf, F, Angleitner, A. et al. (1999). Age differences in personality across the adult life span: Parallels in five cultures. Developmental Psychology, 35, 466-477.

McCrae, R. R., Costa, P. T.Jr. Terracciano, A., Parker, W. D., Mills, C. J., De Fruyt, F., \& Mervielde, I. (2002). Personality trait development from age 12 to age 18: Longitudinal, cross-sectional and cross-cultural analyses. Journal of Personality and Social Psychology, 83, 1456-1468.

Mehta, P. D., \& West, S. G. (2000). Putting the individual back into individual growth curves. Psychological Methods, 5, 23-43.

Mroczek, D. K., \& Spiro, A, III. (2003). Modeling intraindividual change in personality traits: Findings from the normative aging study. Journals of Gerontology: Psychological Sciences, 58B, $153-165$.

Paikoff, R. L., \& Brooks-Gunn, J. (1991). Do parent-child relationships change during puberty? Psychological Bulletin, 110, 47-66.

Petersen, A. C., Crockett, L., Richards, M. H., \& Boxer, A. M. (1988). A self-report measure of pubertal status: Reliability, validity, and initial norms. Journal of Youth and Adolescence, 17, $117-$ 133.

Porteous, M. A. (1985). Developmental aspects of adolescent problem disclosure in England and Ireland. Journal of Child Psychology and Psychiatry and Allied Disciplines, 26, 465-478.

Raudenbush, S. W., \& Chan, W. S. (1993). Application of a hierarchical linear model to the study of adolescent deviance in an overlapping cohort design. Journal of Consulting and Clinical Psychology, 61, 941-951.

Roberts, B. W., Walton, K. E., \& Viechtbauer, W. (2006a). Patterns of mean-level change in personality traits across the life course: A meta-analysis of longitudinal studies. Psychological Bulletin, 132, 1-25.

Roberts, B. W., Walton, K. E., \& Viechtbauer, W. (2006b). Personality traits change in adulthood: Reply to Costa and McCrae (2006). Psychological Bulletin, 132, 29-32.

Robins, R. W., Fraley, R. C., Roberts, B. W., \& Trzesniewski, K. H. (2001). A longitudinal study of personality change in young adulthood. Journal of Personality, 69, 617-640.

Scholte, R. H. J., van Lieshout, C. F. M., \& van Aken, M. A. G. (2001). Perceived relational support in adolescence: Dimensions, configurations, and adolescent adjustment. Journal of Research on Adolescence, 11, 71-94.

Silberman, M. A., \& Snarey, J. (1993). Gender differences in moral development during early adolescence: The contribution of sex-related variations in maturation. Current Psychology: Developmental, Learning, Personality, Social, 12, 163-171. 
Small, B. J., Hertzog, C., Hultsch, D. F., \& Dixon, R. A. (2003). Stability and change in adult personality over 6 years: Findings from the Victoria Longitudinal Study. Journals of Gerontology: Psychological Sciences \& Social Sciences, 58B, 166-176.

Srivastava, S., John, O. P., Gosling, S. D., \& Potter, J. (2003). Development of personality in early and middle adulthood: Set like plaster or persistent change? Journal of Personality and Social Psychology, 84, 1041-1053.

Terracciano, A., McCrae, R. R., Brant, L. J., \& Costa, P. T., Jr. (2005). Hierarchical linear modeling analyses of the NEO-PI-R scales in the Baltimore longitudinal study of aging. Psychology and Aging, 20, 493-506.

Twenge, J. M. (2000). The age of anxiety? The birth cohort change in anxiety and neuroticism, 19521993. Journal of Personality and Social Psychology, 79, 1007-1021.

Twenge, J. M. (2001). Birth cohort changes in extraversion: A cross-temporal meta-analysis, 19661993. Personality and Individual Differences, 30, 735-748.

Vaidya, J. G., Gray, E. K., Haig, J., \& Watson, D. (2002). On the temporal stability of personality: Evidence for differential stability and the role of life experiences. Journal of Personality and Social Psychology, 83, 1469-1484.

Van Lieshout, C. F. M. (2000). Life-span personality development: Self-organizing goal-oriented agents and developmental outcome. International Journal of Behavioral Development, 24, 276288.

Zuckerman, M., Koestner, R., DeBoy, T., Garcia, T., Maresca, B. C., \& Sartoris, J. M. (1988). To predict some of the people some of the time: A reexamination of the moderator variable approach in personality theory. Journal of Personality and Social Psychology, 54, 1006-1019. 